Supporting Information

\title{
Effects of Pulse Charging by Triboelectric Nanogenerators on the Performance of Solid-state Lithium Metal Batteries
}

\author{
Genrui Qiu, ${ }^{\mathrm{a}, \mathrm{b}}$ Liang Lu, ${ }^{\mathrm{a}}$ Yao Lu, ${ }^{\mathrm{a}, \mathrm{b}}$ Chunwen Sun ${ }^{\mathrm{a}, \mathrm{b}, *}$
}

${ }^{a}$ CAS Center for Excellence in Nanoscience, Beijing Institute of Nanoenergy and Nanosystems, Chinese Academy of Sciences, Beijing 100083, P. R. China.

${ }^{\mathrm{b}}$ School of Nanoscience and Technology, University of Chinese Academy of Sciences, Beijing 100049, P. R. China.

${ }^{*}$ Corresponding author.

Email: sunchunwen@binn.cas.cn (C. Sun)

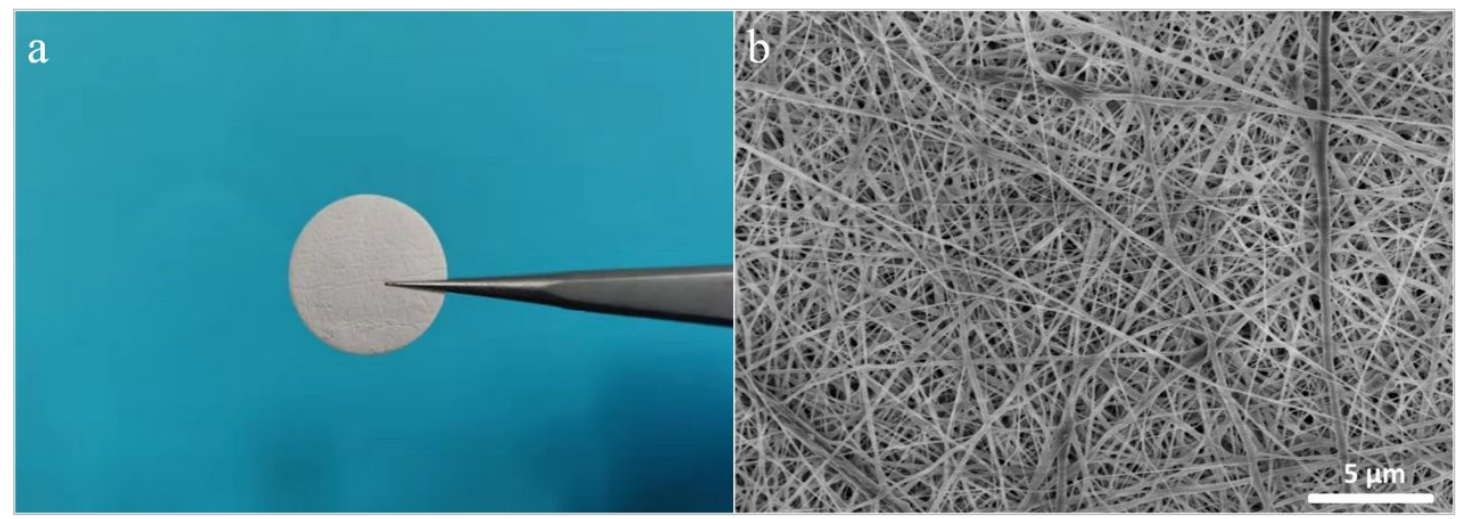

Figure S1. (a) Photo of the hybrid solid electrolyte membrane. (b) SEM image of the hybrid solid electrolyte membrane. 


\section{$\mathrm{LiFePO}_{4}$ cathode}

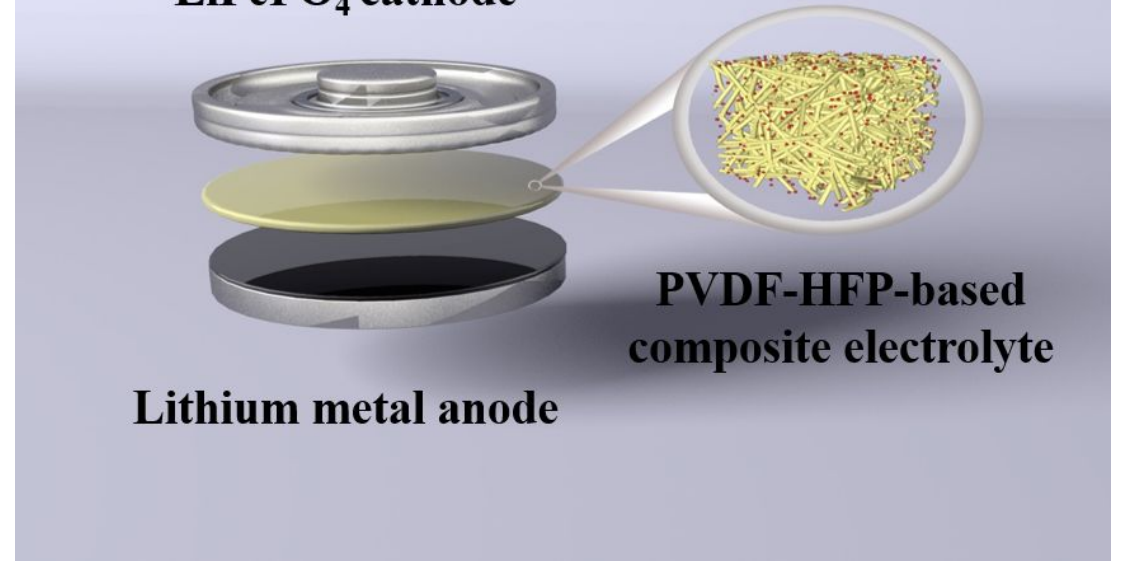

Figure S2. The schematic diagram of $\mathrm{LiFePO}_{4}|\mathrm{HSE}| \mathrm{Li}$ cell. 


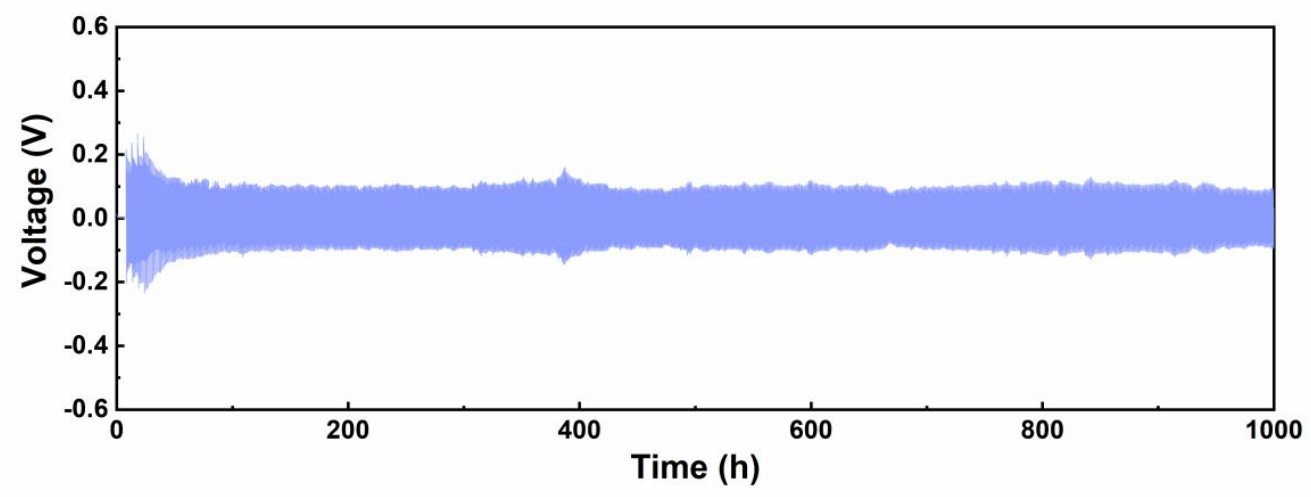

Figure S3. Voltage profile of the lithium plating/stripping cycling in the symmetrical Li|HSE|Li cell. 


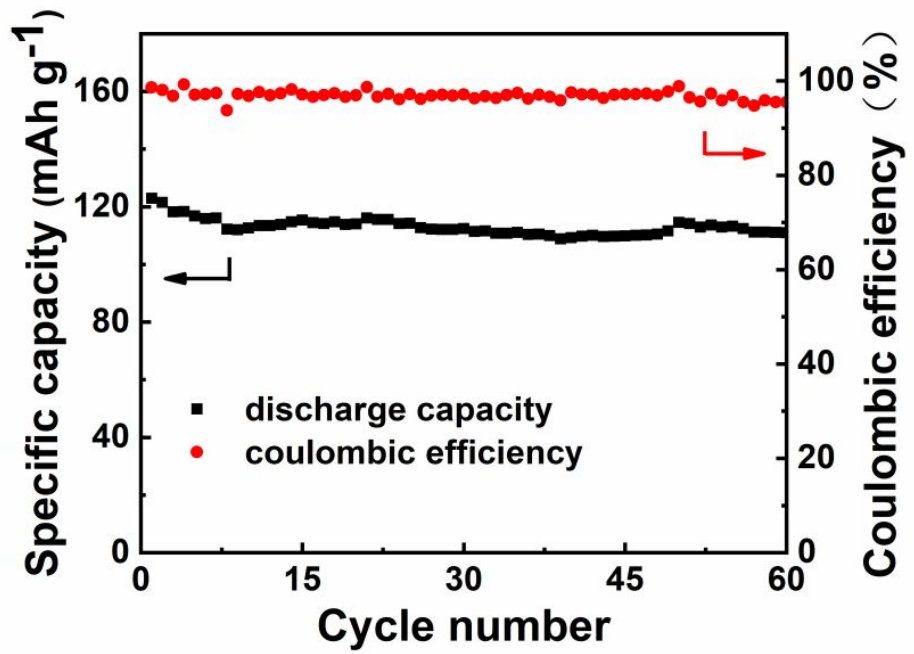

Figure S4. Long-term cycling performance of the flexible battery at $0.2 \mathrm{C}$ rate: the capacity and Coulombic efficiency versus cycle number. 


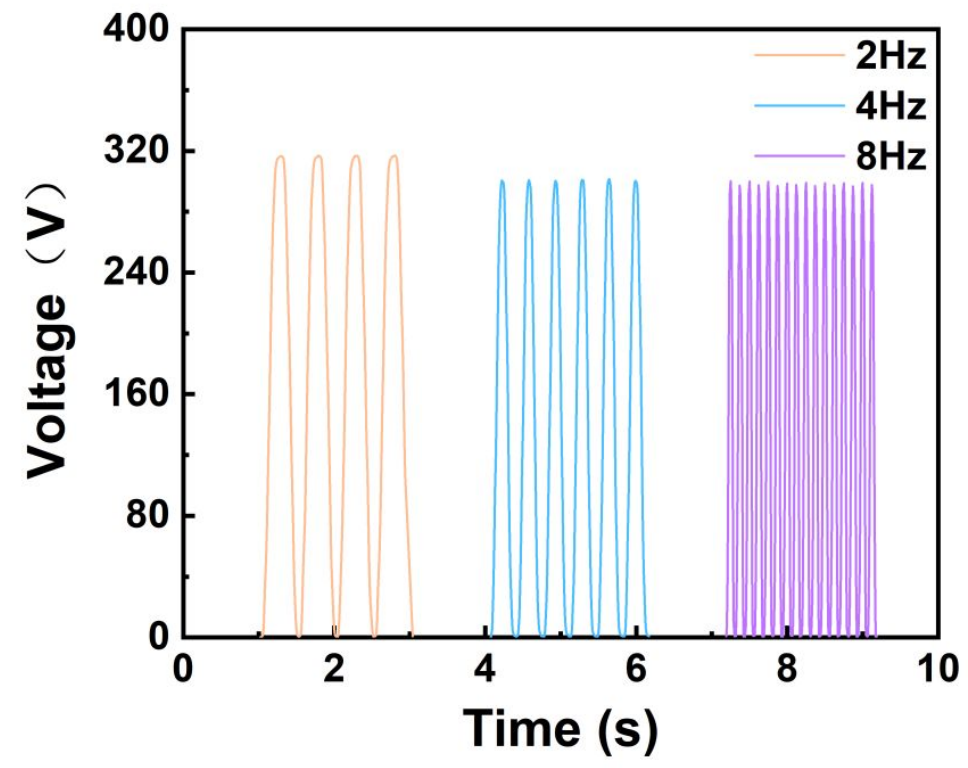

Figure S5. Open-circuit voltages of the TENG at different frequencies. 


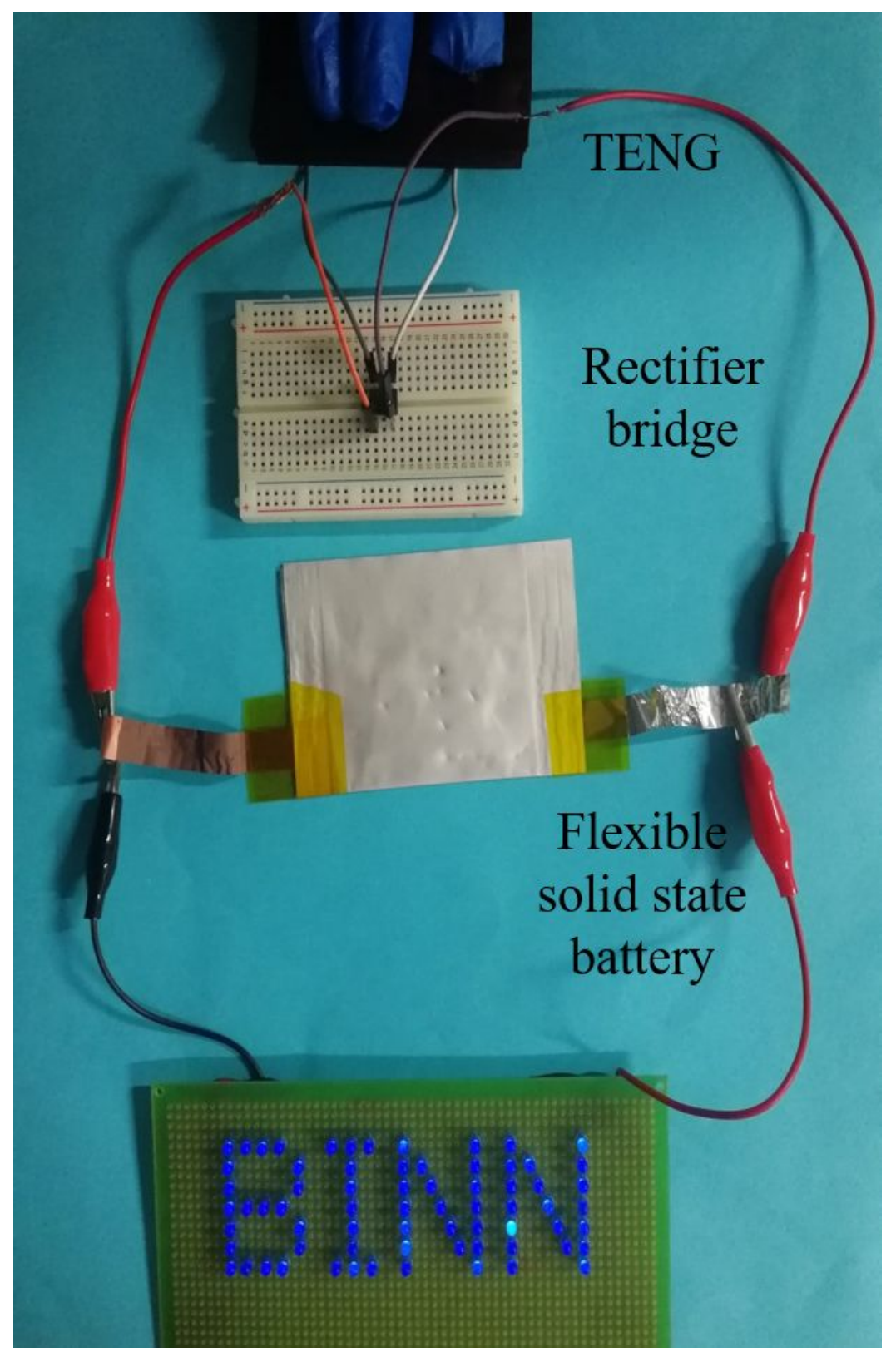

Figure S6. Photo of TENG charging the flexible battery to light the LED screen. 

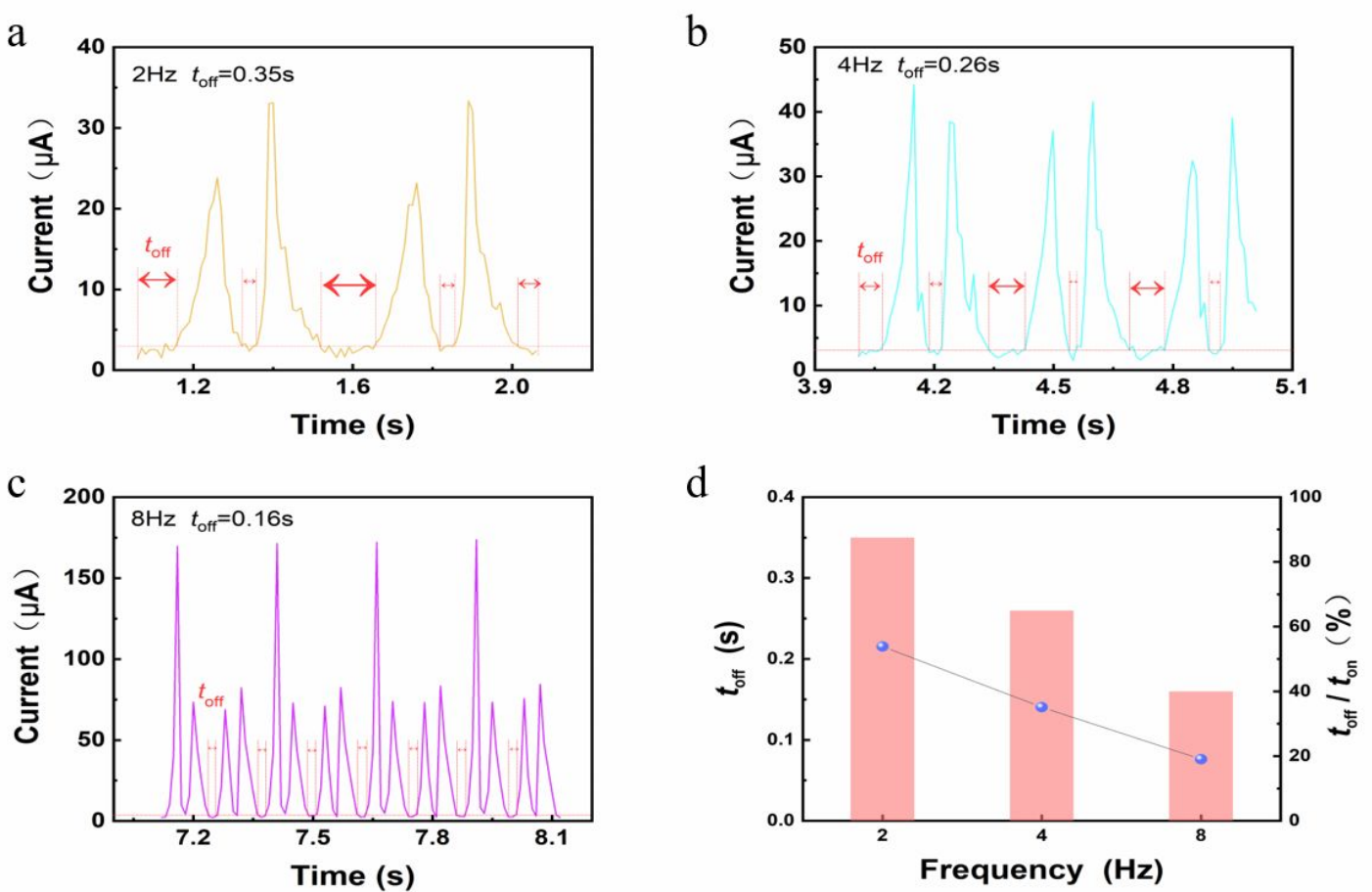

Figure S7. (a) Break time of short-circuit current of the TENG at $2 \mathrm{~Hz}$. (b) Break time of short-circuit current of the TENG at $4 \mathrm{~Hz}$. (c) Break time of short-circuit current of the TENG at $8 \mathrm{~Hz}$. (d) Comparison of $t_{\text {off }} / t_{\text {on }}$ at different frequencies. 